\title{
Uncertainty and the IPCC. An editorial comment
}

\author{
Mort Webster
}

Accepted: 13 November 2008 / Published online: 9 December 2008

(C) Springer Science + Business Media B.V. 2008

In this issue, Swart et al. (2009) provide a useful review of how uncertainty has been treated in the assessments of the Intergovernmental Panel on Climate Change (IPCC), and how this treatment has evolved over time. They also recommend a series of improvements for future IPCC assessments, with which I am substantially in agreement. In this essay, I will emphasize three points on how to communicate uncertainty through the IPCC process.

The first point is with regard to the treatment of uncertainty within Working Group IIII (WG III). Swart et al. highlight the relatively sparse description of uncertainties in WG III relative to that of WG I and II. While I do not disagree, I would argue that part of the solution is for the community to produce more instances of rigorous analysis of uncertainty for their respective models and projections. The primary role of the IPCC is not to perform new analyses, but to summarize the literature. Thus, if there are only few uncertainty analyses of emissions or mitigation cost projections, no guidance to IPCC authors will compensate. Examples of formal uncertainty analyses do exist (e.g., Webster et al. 2008; Manne and Richels 1994; Nordhaus and Yohe 1983; Nordhaus and Popp 1997; Reilly et al. 1987; Scott et al. 1999), but have been relatively rare compared to the number of analyses that neglect uncertainty. Formal uncertainty analysis of socio-economic models is difficult and costly, in part for the reasons outlined by Swart et al. Nevertheless, the community at large is responsible for providing the basis of future assessments.

The second point that I wish to echo from Swart et al. is that the supposed distinction between seemingly objective physical science uncertainties and the more readily apparent subjectivity of social science uncertainties is less clear than many would like to believe. Clearly, the issue of intentionality (i.e., free will among the

M. Webster $(\varangle)$

Engineering Systems Division,

Massachusetts Institute of Technology, E40-235,

77 Massachusetts Avenue, Cambridge, MA 02139, USA

e-mail: mort@mit.edu 
objects of study), adds a complication to socioeconomic analysis that does not exist in physical systems. Aside from that issue, however, the distinction blurs. The lack of global uniform coverage of earth observation systems results in the necessity of data reanalysis, based on reasonable but nevertheless subjective assumptions.

One example of this phenomenon is the record of ocean temperatures over the $20^{\text {th }}$ century at depth. The ocean temperature data assembled by Levitus et al. (2005) has been reanalyzed by several different authors (e.g., Gouretski and Koltermann 2007; Domingues et al. 2008) making alternative plausible assumptions about how to correct for observational errors and instrument bias. The resulting trends in ocean warming have a significant impact on whether and how one can constrain future projections of global mean temperature because of their implications for the rate heat uptake by the deep ocean (Sokolov et al. 2008).

The point here is that subjectivity of assumptions is a necessary part of assessment across all disciplines that are relevant to climate change. IPCC assessments that attempt to characterize and communicate uncertainty must combine expert elicitation and other "subjective" measures of uncertainty with seemingly precise uncertainty ranges from data sets or model simulations.

One example from the 4th Assessment Report (AR4) is instructive here. The WG I Summary for Policymakers (SPM) of AR4 describes the uncertainty in a rise in sea level of between 18 and $59 \mathrm{~cm}$ by the year 2100 (IPCC 2007a), which is a "modelbased range" composed largely of thermal expansion of oceans, melting of nonpolar glaciers, and the gradual response of ice sheets. The range does not include the potential for increasing contributions from rapid dynamic processes in the Greenland and West Antarctic ice sheets (WAIS), which have already had a significant effect on sea level over the past 15 years and could eventually raise sea level by many meters. Lacking such processes, models cannot fully explain observations of recent sea-level rise, and accordingly, projections based on such models may seriously understate potential future increases (Oppenheimer et al. 2007, 2008). Although the AR4 WG I SPM recognizes the possibility of a larger ice-sheet contribution, its main quantitative results indicate the opposite: Uncertainty in sea-level rise is smaller, and its upper bound is lower, for the twenty-first century than was indicated in the Third Assessment Report (IPCC 2001).

Given recent concern over the current generation ice sheet models, it is understandable why the authors would give a numerical uncertainty range that omits WAIS and Greenland. However, this approach of restricting uncertainty statements, especially in the SPM, can have disastrous unintended consequences. In a recent editorial in the Wall Street Journal, Lomborg writes that "The United Nations science consensus expects temperature increases of 3 to 7 degrees Fahrenheit by the end of the century, leading to (for example) sea-level increases of between one-half and two feet. Yet such a rise is entirely manageable and not dissimilar to the sealevel rise of about one foot we dealt with over the past 150 years." (Lomborg 2008). This deeply misleading conclusion is unfortunately completely defensible given the numerical range in the AR4 SPM.

It is important to note that WG II reached a strikingly different conclusion regarding the uncertainty in sea level rise in its SPM than did WG I (Schneider et al. 2007). WG II includes the statement that, "There is medium confidence that at least partial deglaciation of the Greenland ice sheet, and possibly the West Antarctic ice sheet, would occur over a period of time ranging from centuries to millennia for 
a global average temperature increase of $1-4^{\circ} \mathrm{C}$ (relative to 1990-2000), causing a contribution to sea level rise of 4-6 m or more." (IPCC 2007b). The presence of this statement in WG I and of a qualitative compromise statement in the overall synthesis report are not sufficient to prevent the misinterpretation of the WG I uncertainty range.

My third and final point, therefore, is that future IPCC assessments must be even more thorough about informing numerical uncertainty ranges with multiple sources of that uncertainty, not limiting them to available models, and for making these sources as transparent as possible. However well-meaning, attempts to define consistent words for likelihood judgment consumed much time in previous assessment rounds, and in the end evidence has shown that readers define their meaning anyway (Patt and Schrag 2003; Patt and Dessai 2005). Where future IPCC efforts need to be focused is on making sure that all sources of uncertainty have been included and reflected in the numerical ranges on which public discourse will inevitably focus. The consistency that is needed across chapters and across working groups is not that about specific words, but about the paradigmatic approach to uncertainty and risk management. Despite the legitimate differences between disciplines, a shared view of the relative importance of avoiding type I vs. type II errors is both achievable and critically important.

In the past two decades, the IPCC's emphasis on consensus was necessary, and has served to help shift public opinion. Going forward, governments now need careful assessments of the relative risks of impacts and costs. Treatment of uncertainty will become more important than consensus if the IPCC is to stay relevant to the decisions that face us.

\section{References}

Domingues CM, Church JA, White NJ, Gleckler PJ, Wijffels SE, Barker PM, Dunn JR (2008) Improved estimates of upper-ocean warming and multi-decadal sea-level rise. Nature 453(7198):1090-1093, 19 June 2008. doi:10.1038/nature07080

Gouretski V, Koltermann KP (2007) How much is the ocean really warming? Geophys Res Let 34:L01610. doi:10.1029/2006GL027834

IPCC (2001) Summary for policymakers. In: Houghton JT et al (eds) Climate change. The physical science basis. Cambridge Univ. Press, Cambridge, pp 1-20

IPCC (2007a) Summary for policymakers. In: Solomon S et al (eds) Climate change. The physical science basis: contribution of Working Group I to the Fourth Assessment Report of the Intergovernmental Panel on Climate Change. Cambridge Univ. Press, New York, pp 1-18

IPCC (2007b) Summary for policymakers. In: Parry M et al (eds) Climate change. Impacts, adaptation, and vulnerability: contribution of Working Group II to the Fourth Assessment Report of the Intergovernmental Panel on Climate Change. Cambridge Univ. Press, New York, pp 7-22

Levitus S, Antonov J, Boyer TP (2005) Warming of the world ocean, 1955-2003. Geophys Res Let 32:L02604. doi:10.1029/2004GL021592

Lomborg B (2008) A new dawn. Wall Street J. 8 November 2008

Manne AS, Richels RG (1994) The costs of stabilizing global $\mathrm{CO}_{2}$ emissions: a probabilistic analysis based on expert judgment. Energy J 15(1):31-56

Nordhaus WD, Popp D (1997) What is the value of scientific knowledge? An application to global warming using the price model. Energy J 18(1):1-45

Nordhaus WD, Yohe GW (1983) Future carbon dioxide emissions from fossil fuels. In: Changing climate, report of the carbon dioxide assessment committee. National Academy Press, Washington, DC, pp 87-153 
Oppenheimer M, O'Neill BC, Webster MD, Agrawala S (2007) The limits of consensus. Science 317(5844):1505-1506, 14 September 2007

Oppenheimer M, O'Neill BC, Webster MD (2008) Negative learning and global environmental change. Clim Change 89(1-2):155-172

Patt A, Dessai S (2005) Communicating uncertainty: lessons learned and suggestions for climate change assessment. Compte Rendus Geosciences 337:427-441

Patt AG, Schrag D (2003) Using specific language to describe risk and probability. Clim Change 61:17-30

Reilly J, Edmonds J, Gardner R, Brenkert A (1987) Monte Carlo Analysis of the IEA/ORAU Energy/Carbon Emissions Model. Energy J 8(3):1-29

Schneider SH, Semenov S, Patwardhan A, Burton I, Magadza CHD, Oppenheimer M, Pittock AB, Rahman A, Smith JB, Suarez A, Yamin F (2007) Assessing key vulnerabilities and the risk from climate change. In: Parry ML, Canziani OF, Palutikof JP, van der Linden PJ, Hanson CE (eds) Climate change 2007: impacts, adaptation and vulnerability. Contribution of Working Group II to the Fourth Assessment Report of the Intergovernmental Panel on Climate Change. Cambridge University Press, Cambridge, UK, pp 779-810

Scott MJ, Sands RD, Edmonds J, Liebetrau AM, Engel DW (1999) Uncertainty in integrated assessment models: modeling with MiniCAM 1.0. Energy Policy 27(14):597

Sokolov AP, Stone PH, Forest CE, Prinn R, Sarofim MC, Webster M, Paltsev S, Schlosser CA, Kicklighter D, Dutkiewicz S, Reilly J, Wang C, Felzer B, Jacoby HD (2008) Probabilistic forecast for 21st century climate based on uncertainties in emissions (without Policy) and Climate Parameters. MIT Joint Program Report \#166, Cambridge, MA

Swart RR et al. (2009) Agreeing to disagree: uncertainty management in assessing climate change, impacts and responses by the IPCC. Clim Change 92:1-2

Webster M, Paltsev S, Parsons J, Reilly J, Jacoby H (2008) Uncertainty in greenhouse emissions and costs of atmospheric stabilization. MIT Joint Program Report \#165, Cambridge, MA 